\title{
Changes in snoring characteristics after 30 days of nasal continuous positive airway pressure in patients with non-apnoeic snoring: a controlled trial
}

F Sériès, I Marc

\begin{abstract}
Background - A study was performed to evaluate the effect of discontinuation of nasal continuous positive airway pressure (NCPAP) treatment on snoring characteristics.

Methods - Eighteen non-apnoeic snoring subjects were randomly allocated to either a no treatment control group or an NCPAP treatment group. The control group was studied twice (baseline and day 30 of follow up). In the NCPAP group the level of NCPAP that abolished snoring was determined and patients were placed on NCPAP every night for one month. A sleep study was performed on the first night without NCPAP after completing 30 days of treatment (follow up 1). A fourth polysomnographic study was performed 8-10 days after NCPAP was stopped (follow up 2) in six subjects. Results - In both groups total sleep time (TST) and sleep architecture remained unchanged at the different visits. Baseline snoring characteristics in the two groups were similar. In the control group the mean (SE) number of snoring episodes/hour of sleep (snoring index) and

related nocturnal desaturations, apnoea related haemodynamic disturbances, and returns sleep architecture to normal. These effects account for the reduction in sleep apnoea related morbidity. ${ }^{23}$

Snoring can be suppressed by NCPAP, ${ }^{4}$ a beneficial effect related to the pneumatic splinting of pharyngeal walls and the prevention of fluttering of upper airway structures. The need to wear a nasal mask connected to a compressor every night might discourage snorers and their bed partners, however, so NCPAP is not routinely used to treat snoring alone.

Recent reports suggest that the benefits of NCPAP may continue after its cessation in patients with the sleep apnoea hypopnoea syndrome, ${ }^{56}$ and that this prolonged effect can be attributed to an improvement in upper airway patency. ${ }^{7}$ The transient improvements in sleep related obstructive breathing disorders seen after NCPAP could be explained by a selfaggravation of these events by upper airway tissue damage that is reversible when an effective treatment is applied. The aim of the study was to verify if an improvement in snoring characteristics seen after NCPAP would occur in non-apnoeic snorers.
\end{abstract} the percentage of TST $>60$ decibels (dB) were $380(36) / h$ and $11 \cdot 1 \quad(2.0) \%$ TST respectively at baseline, and was unchanged at follow up. In the NCPAP group the snoring index decreased from $387(50) / h$ to 320 (57)/h after NCPAP therapy, but the \% TST $>60 \mathrm{~dB}$ decreased from $10.3(1.8) \%$ to $7.4(1.5) \%$. The snoring index and intensity returned to baseline values at follow up $2(374(74) / h, 9 \cdot 8$ $(2 \cdot 1) \%$ TST). Changes in snoring characteristics could not be explained by changes in body position between the different sleep studies.

Conclusions - NCPAP improves snoring but this effect is lost soon after stopping treatment.

(Thorax 1994;49:562-566)

Nasal continuous positive airway pressure (NCPAP) was first proposed as a treatment for the sleep apnoea hypopnoea syndrome in $1981^{1}$ and it is still considered the most effective treatment for this condition. Besides its dramatic effects on sleep related obstructive breathing disorders, NCPAP improves apnoea

\section{Methods}

SUBJECTS

Eighteen non-apnoeic snoring subjects (16 men, two women, age range $25-64$ years, mean (SE) body mass index: $\left.29 \cdot 1(1 \cdot 0) \mathrm{kg} / \mathrm{m}^{2}\right)$ were included in the study. Four were smokers. All had a history of regular snoring confirmed by family or friends and were free of upper airway infection throughout the study. In order to exclude the diagnosis of the sleep apnoea hypopnoea syndrome all the patients had a previous polysomnographic study (apnoea + hypopnoea index: $3 \cdot 7(0.8) / \mathrm{h})$ with snoring measurement. None had undergone treatment for snoring nor were any taking medication at the time of the study.

PROTOCOL

Patients were randomly allocated to two groups paired for snoring index (see below). One group (control) received no specific treatment but underwent a second polysomnographic study 30 days after the initial study (follow up). In the other group (NCPAP 
group) patients were treated at home by NCPAP every night for 30 days. Three patients in this group stopped the treatment after a few days because of discomfort and were replaced by patients with identical snoring indices. The NCPAP level was determined during a second sleep study performed within a few days of the first study. Positive pressure level was increased until snoring was abolished. NCPAP equipment was provided by ARS Vital Aire (Montreal, Quebec, Canada). Subjects were asked to contact the sleep laboratory if they had any trouble with the apparatus. A third sleep study was obtained on the first night without NCPAP after the 30 days of treatment (follow up 1). Six subjects from the NCPAP group also agreed to a fourth study 8 10 days after the end of the NCPAP period (follow up 2). Subjects were asked to avoid alcohol consumption for a minimum of 12 hours before each recording session. The experimental protocol was approved by our ethics committee, and each subject provided signed informed consent prior to participation in the study.

\section{RECORDING PROCEDURE}

The same procedure was used as previously described. ${ }^{8}$ Two microphones (Shure SM 58, Evanston, Illinois, USA) were placed symmetrically on each side of the bed, $70 \mathrm{~cm}$ above the bed surface and $85 \mathrm{~cm}$ apart, and angled to point directly toward the centre of the bed at the normal head position. The signal was preamplified, mixed, equalised (see Calibration procedure) and analysed with a spectrum analyser (RTA SA 3050, Audio Control, Mountlake Terrace, Washington, USA) to get the snoring sound pressure level (decibel: $\mathrm{dB}$ SPL). The SPL was displayed on the Grass recorder and transferred to a microcomputer at a $60 \mathrm{~Hz}$ sampling frequency for automatic interpretation of the SPL data. The snoring recording was started at sleep onset and interrupted during the night for every nocturnal awakening.

Snoring recordings were performed during polysomnographic sleep studies that included the determination of sleep stages (electroencephalogram $C_{4} A_{1}, C_{3} A_{2}$; electrooculogram; submental electromyogram), nasal and mouth airflow with thermocouples (Grass Instruments, Quincy, Massachusetts, USA), $\mathrm{SaO}_{2}$ with a Criticare 504 ear oximeter (CSI, Waukesha, Wisconsin, USA), electrocardiogram, thoracoabdominal movements by respiratory inductive plethysmography (Respitrace, Ambulatory Monitoring, Ardsley, New York, USA) calibrated by the isovolume method. ${ }^{9}$ The snoring SPL tracing was displayed continuously. All parameters were recorded on a 16-channel polygraph (Model 78; Grass Instruments, Quincy, Massachusetts, USA) at a paper speed of $10 \mathrm{~mm} / \mathrm{s}$. Sleep position was determined by visual monitoring using an infrared camera.

\section{CALIBRATION AND INTERPRETATION}

PROCEDURES

To take into account the acoustic characteristics of the recording system (variations due to the acoustic resonances of the bedroom as well as the recording system) a calibration of the sound signal preceded the sleep studies. ${ }^{8}$ An equalisation procedure was performed on a Pink Noise (PN) generated by a speaker (Koss M65, Koss Corporation, Milwaukee, Wisconsin, USA) placed at the normal head position and measured at $77 \mathrm{~dB}$ SPL by a calibrated microphone (Audio Control CM 10) with the RTA spectrum analyser before each recording session. It consisted of adjusting the different frequency bands of a third octave graphic equaliser (DOD R 831, Salt Lake City, Utah, USA) until the RTA display of $77 \mathrm{~dB}$ SPL PN gave a flat $\pm 2 \mathrm{~dB}$ SPL response from 80 and $16000 \mathrm{~Hz}$. The sensitivity of the equaliser was then adjusted to give the $\mathrm{PN}$ an intensity of $77 \mathrm{~dB}$ SPL. Following this procedure the equalised signal of the breathing noise was analysed by the spectrum analyser and transferred to the computer for interpretation. This was done after the calibration of the acquisition program had been checked by determining the computer measured SPL of one minute $77 \mathrm{~dB}$ SPL PN recording. When taking into account the accuracy of each component of the recording system and the error related to variation in the distance between the subject and microphone, the cumulative error was estimated at $\pm 2 \mathrm{~dB}$.

DATA COLLECTION AND STATISTICAL ANALYSIS Polysomnographic recordings were manually analysed in 30 second epochs and sleep stages and respiratory events were defined by standard criteria. ${ }^{111}$ An arousal was defined as the simultaneous transition to a lighter sleep stage with eye movements and an increase in electromyographic activity of less than 15 seconds. ${ }^{12}$ Snoring was defined as a spike in breathing sound intensity greater than $60 \mathrm{~dB}$ SPL. We chose this threshold because the background noise level in the test rooms could reach $50 \mathrm{~dB}$ and normal breathing SPL could go up to $54 \mathrm{~dB}$ SPL. This definition of snoring is similar to that previously used by Hoffstein $e t$ al. ${ }^{1314}$ For each recording a computer interpretation of the sound recording gave the snoring index (number of snoring episodes/ hour of sleep), the total sleep time (TST) spent at the different SPL values in $3 \mathrm{~dB}$ steps above $60 \mathrm{~dB}$ SPL (60-72 dB SPL), and the mean snoring level.

Since the number of visits differed between the two groups, the results obtained in the control and NCPAP groups were compared separately. Since our data were normally distributed, parametric tests were used. Data expressed as percentages were transformed to obtain an underlying normal distribution. ${ }^{15}$ Baseline results of the two groups were compared by the unpaired $t$ test. In the control group baseline and follow up results were compared with a paired $t$ test. The results obtained at the different visits in the NCPAP 
Mean (SE) results of the sleep studies obtained at the different visits.

\begin{tabular}{|c|c|c|c|c|c|c|}
\hline & \multicolumn{2}{|c|}{ Control group } & \multicolumn{4}{|c|}{ NCPAP group } \\
\hline & Baseline & Follow up & Baseline & $N C P A P$ & Follow up 1 & Follow up 2 \\
\hline $\begin{array}{l}\text { TST (h) } \\
\text { Stages I-II }(\% \text { TST) } \\
\text { Stages III-IV (\% TST) } \\
\text { Stages REM }(\% \text { TST) } \\
\text { Apnoea +hypopnoea index }(\text { no } / \mathrm{h}) \\
\text { Arousal index (no/h) } \\
\text { Supine }(\% \text { TST) }\end{array}$ & $\begin{array}{r}6 \cdot 2(0 \cdot 2) \\
72 \cdot 0(1 \cdot 5) \\
15 \cdot 0(1 \cdot 6) \\
13 \cdot 0(0.9) \\
4.5(1 \cdot 3) \\
8 \cdot 6(1 \cdot 6) \\
49 \cdot 0(9 \cdot 0)\end{array}$ & $\begin{array}{r}6 \cdot 3(0 \cdot 3) \\
71.9(1 \cdot 2) \\
14.4(0.8) \\
13 \cdot 7(1 \cdot 1) \\
5 \cdot 1(1 \cdot 2) \\
9.9(1 \cdot 7) \\
42 \cdot 3(6 \cdot 8)\end{array}$ & $\begin{array}{r}5 \cdot 7(0.3)^{\mathrm{a}} \\
71.9(1.2)^{\mathrm{a}} \\
13.8(0.9)^{\mathrm{a}} \\
14.2(0.5)^{\mathrm{a}} \\
2.9(1.3)^{\mathrm{a}} \\
9 \cdot 7(1.3)^{\mathrm{a}} \\
40 \cdot 1(10.4)^{\mathrm{a}}\end{array}$ & $\begin{array}{r}5 \cdot 7(0 \cdot 3)^{\mathrm{a}} \\
71 \cdot 1(1 \cdot 2)^{\mathrm{a}} \\
14 \cdot 6(0.9)^{\mathrm{a}} \\
14 \cdot 3(1 \cdot 0)^{\mathrm{a}} \\
0 \cdot 2(0 \cdot 2)^{\mathrm{b}} \\
3 \cdot 7(0 \cdot 8)^{\mathrm{b}} \\
21 \cdot 0(5 \cdot 0)^{\mathrm{a}}\end{array}$ & $\begin{array}{l}6 \cdot 0(0 \cdot 1)^{\mathrm{a}} \\
72 \cdot 3(1 \cdot)^{\mathrm{a}} \\
13 \cdot 0(1 \cdot 1)^{\mathrm{a}} \\
14 \cdot 6(0 \cdot 9)^{\mathrm{a}} \\
1 \cdot 0(0 \cdot 5)^{\mathrm{ab}} \\
8 \cdot 2(1 \cdot 4)^{\mathrm{a}} \\
29 \cdot 2(6 \cdot 7)^{\mathrm{a}}\end{array}$ & $\begin{array}{r}6 \cdot 1(0 \cdot 5)^{\mathrm{a}} \\
72 \cdot 1(1 \cdot 0)^{\mathrm{a}} \\
13 \cdot 7(0 \cdot 7)^{\mathrm{a}} \\
14 \cdot 2(1 \cdot 0)^{\mathrm{a}} \\
1 \cdot 1(0 \cdot 5)^{\mathrm{ab}} \\
6 \cdot 9(1 \cdot 6)^{\mathrm{a}} \\
16 \cdot 0(4 \cdot 8)^{\mathrm{a}}\end{array}$ \\
\hline
\end{tabular}

TST $=$ total sleep time $;$ NCPAP $=$ nasal continuous positive airway pressure

In the NCPAP group the 30 day visit was the first night without NCPAP for the previous month. In the control group there was no difference between baseline and follow up visit. In the NCPAP group data followed by different letters are significantly different.

group were compared with baseline values by multivariate analysis of variance followed by Tukey's test for multiple comparison for each variable. Since the individual values of the \% TST spent at the different noise levels were dependent, the significance threshold was determined according to the Bonferroni criteria $(\mathrm{p}<0.01)$.

\section{Results}

The results of the sleep studies obtained at the different visits are summarised in the table. In both groups TST and sleep architecture remained unchanged at the different visits. There was no difference in baseline snoring characteristics between the two groups. In the control group the snoring index remained
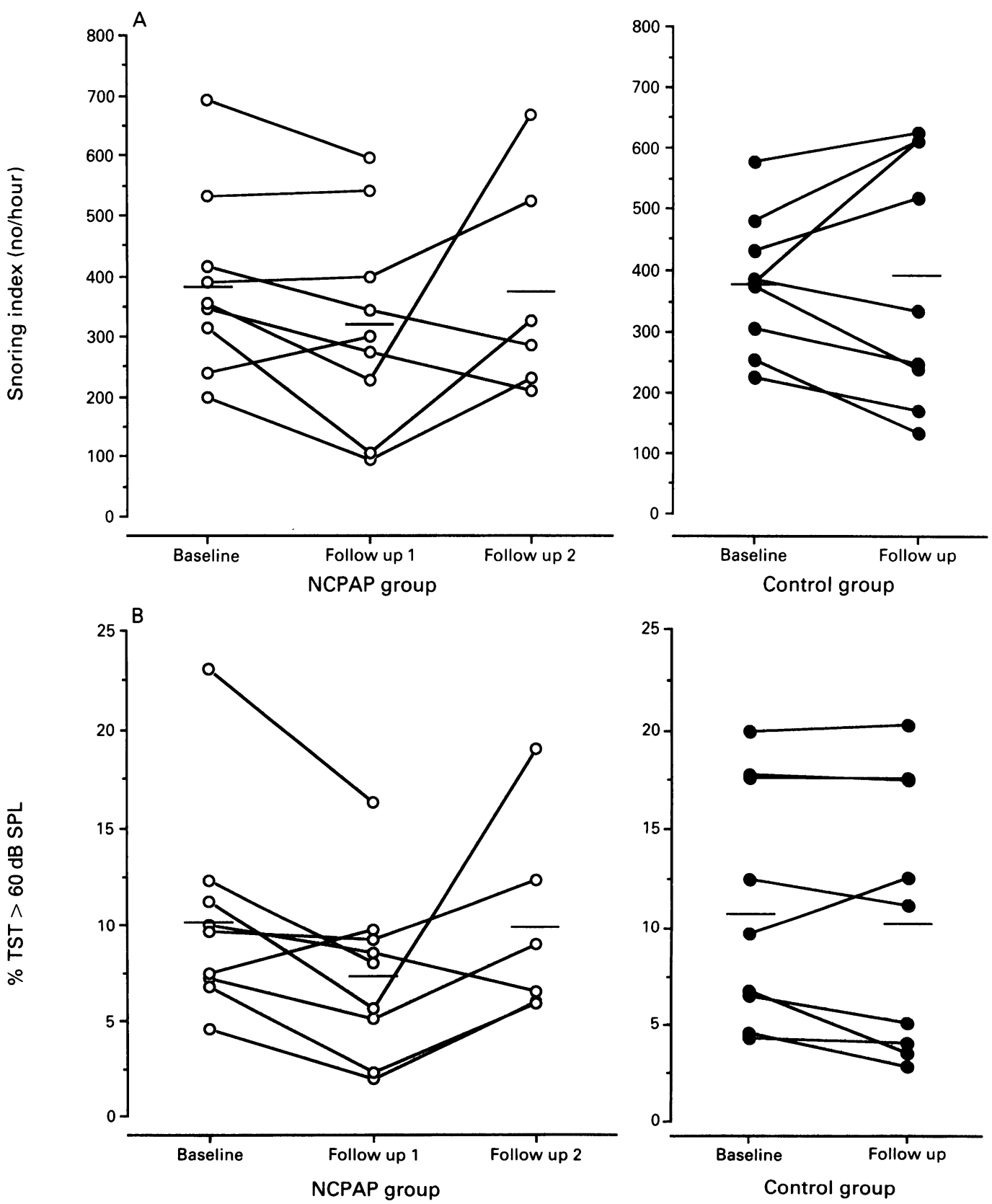

Individual values of $(A)$ the snoring index and $(B)$ the percentage of total sleep time (TST) $>60 \mathrm{~dB}$ sound pressure level (SPL) obtained at the different visits in the control and NCPAP groups. Horizontal lines represent mean values. 
unchanged at the two visits $(380(36) / \mathrm{h}$ and 388 $(67) / h$ ) (figure, A). The $\%$ TST spent at the different $\mathrm{dB}$ levels was identical at baseline and at follow up (\% TST > $\% 0 \mathrm{~dB}$ SPL: $11 \cdot 1$ $(2.0) \%$ at baseline and $10.5(2.3) \%$ at follow up) (figure, B). The mean snoring level was $65.6(0.3) \mathrm{dB}$ SPL at baseline and $65 \cdot 1(0.5) \mathrm{dB}$ SPL at follow up.

Snoring was abolished by NCPAP in every subject in this group (snoring index 15.1 (2.5)/ h) with a mean effective NCPAP level of $5 \cdot 3$ $(0.5) \mathrm{cm} \mathrm{H}_{2} \mathrm{O}$ (range $3-8 \mathrm{~cm} \mathrm{H}_{2} \mathrm{O}$ ). This was confirmed at home by bed partners during the month of NCPAP therapy. In the NCPAP group sleep position varied between different visits but the difference was not significant (table). The decrease in the snoring index after NCPAP therapy from 387 (50)/h to $320(57) / \mathrm{h}$ was not significant (figure, A). The $\%$ TST $>60 \mathrm{~dB}$ SPL improved significantly at follow up $1(\%$ TST $>60 \mathrm{~dB}$ SPL $10.3(1.8) \%$ at baseline and $7.4(1.5) \%$ at follow up; $p=0.02)$ (figure, B). This improvement was observed for sound pressure levels up to $69 \mathrm{~dB}$ SPL. The mean snoring level significantly decreased from $66.4(0.3) \mathrm{dB}$ SPL to $65.0(0.3) \mathrm{dB}$ SPL. The snoring index had returned to baseline values at follow up $2(374(74) / \mathrm{h})$, and the snoring intensity and mean snoring level had also returned to baseline values ( $\%$ TST $>60 \mathrm{~dB}$ SPL $9.8(2 \cdot 1) \%$ and $65.7(0.4) \mathrm{dB}$ SPL respectively). To determine whether our results could be explained by differences in body position between sleep studies we examined the relation between snoring characteristics (snoring index, \% TST > $60 \mathrm{~dB}$ SPL, mean snoring level) and the \% TST supine. There was no correlation between these variables at baseline and at the follow up visits.

\section{Discussion}

Our results show that snoring intensity transiently improves after stopping NCPAP, suggesting that snoring has a reversible component.

The nine subjects in the NCPAP group confirmed that they used the equipment every night during the study period and the three patients who did not tolerate it were replaced. The changes in body position could not account for the improvement in snoring after treatment, and we are confident that our results are not explained by position changes. For these reasons we believe that the improvement was due to NCPAP.

Our study was designed to take into account spontaneous variations in snoring characteristics. We could have used a single blind study using an ineffective NCPAP level in the control group, but several reasons justify our choice: (1) snoring was abolished with a $3 \mathrm{~cm}$ $\mathrm{H}_{2} \mathrm{O}$ pressure level that is the minimal pressure level provided by the NCPAP machines; (2) the lack of efficacy would be obvious to the patients after the first night of home treatment; (3) the compliance with treatment might be poor in the control group sleeping with an ineffective treatment. In our control group snoring frequency and intensity were unchanged despite spontaneous variations in these variables. This variability was less during NCPAP, accounting for the improvement that we noted.

NCPAP was generally well tolerated in our subjects but no subjective change in their sleep quality was reported. In our experience and that of others, the compliance with NCPAP depends on the degree of excessive daytime sleepiness and on its improvement with treatment. ${ }^{16}$ For these reasons long term NCPAP probably does not represent a practical approach to the treatment of asymptomatic snorers. The improvement in snoring characteristics after 30 days of NCPAP treatment was modest. The severity of snoring during polysomnographic recordings may be overestimated compared with home sleep studies, ${ }^{8}$ however, and it is possible that we underestimated the decrease in snoring frequency and intensity during recovery after NCPAP treatment. This is supported by the fact that patients from the NCPAP group reported an improvement at home during the nights after stopping treatment compared with the pretreatment nights. In the sleep apnoea hypopnoea syndrome an improvement in apnoeic/ hypopnoeic events is observed after six months of treatment with NCPAP, ${ }^{56}$ and in our study an improvement occurred after one month. It is not known if the improvement after NCPAP depends on the duration of treatment, and whether similar results could be obtained after a shorter length of treatment.

Several recent reports suggest that the effects of NCPAP may persist after its discontinuation in the sleep apnoea hypopnoea syndrome. Rauscher et al reported that the duration of the longest apnoea decreased when NCPAP was interrupted for part of the night after NCPAP treatment of 6-18 months. ${ }^{5}$ This improvement was greater in patients with the most severe disorders. Leech et al found that the respiratory disturbance index and the average nocturnal saturation significantly improved when NCPAP was discontinued after 3-46 months of treatment. ${ }^{6}$ In these studies the continuing effects of NCPAP could not be explained by changes in body weight, but may be attributable to an improvement in upper airway morphology. ${ }^{7}$

Another explanation for the prolonged effects of NCPAP is the improvement in sleep fragmentation. The electromyographic activity of the genioglossus is depressed after sleep deprivation. ${ }^{17}$ This can increase the apnoea +hypopnoea index after sleep deprivation. ${ }^{18}$ Our results confirm that repetitive arousals can occur in non-apnoeic snorers and that NCPAP effectively corrects these abnormalities. ${ }^{19}$ It is possible that the elimination of sleep fragmentation improves neuromuscular control of the pharynx. The continuing effects of NCPAP on snoring occurred, however, despite a return of the arousal index to the preNCPAP level after the NCPAP interruption.

We conclude that the beneficial effects of NCPAP on snoring can persist after its discontinuation. Reversible factors that aggravate snoring may be involved in a progressive in- 
crease in its severity and contribute to the development of sleep disturbances.

This study was supportd by l'Association Pulmonaire du Québec and The Respiratory Health Network of Centres of Excellence of Canada.

1 Sullivan CE, Issa FG, Berthon-Jones M, Eves L. Reversa of obstructive sleep apnoea by continuous positive airway pressure through the nares. Lancet 1981:ii:862-5.

2 Sullivan CE, Issa FG, Berthon-Jones M, McCauley VB, Costas LVJ. Home treatment of obstructive sleep apnoea with continuous positive airway pressure applied through with continuous positive airway pressure applied through

3 Sarkis S, Derderian MC, Bridenbaugh H, Rajagopal KR. Neurophychologic symptoms in obstructive sleep apne improve after treatment with nasal continuous positive airway pressure. Chest 1988;94:1023-7.

4 Berry RB, Block JA. Positive nasal airway pressure eliminates snoring as well as obstructive sleep apnea. Chest 1984;85:15-20.

5 Rauscher H, Popp W, Wanke T, Zwick H. Breathing during sleep in patients treated for obstructive sleep apnea. Chest 1991;100:156-9.

6 Leech JA, Önal E, Lopata M. Nasal CPAP continues to improve sleep-disordered breathing and daytime oxygenation over long-term follow-up of occlusive sleep pnea syndrome. Chest 1992:102:1651-5.

7 Ryan CF, Lowe AA, Li D, Fleetham JA. Magnetic resonance imaging of the upper airway in obstructive sleep apnea before and after chronic nasal continuous positive airway pressure therapy. Am Rev Respir Dis 1991; 144:939-44

8 Sériès F, Sériès I, Atton L. Comparison of snoring measured at home and during polysomnographic studies. Chest 1993;103:1769-73.

9 Chadha TS, Watson $H$, Birch S, Jenouri GA, Schneider AW, Cohn MA, et al. Validation of respiratory inductive (l)

10 Reschtschaffen A, Kales A, eds. A manual of standardized terminology, techniques and scoring systems for sleep stages of human subjects. Publication no. 204. Bethesda: Nationa Institutes of Health, 1968.

11 Martin RJ. Indications and standards for cardiopulmonary sleep studies. Sleep 1985;8:371-9.

12 American Sleep Disorders Association. EEG arousals: scoring rules and examples. Sleep 1992;15:174-83.

13 Hoffstein V, Rubinstein I, Mateika S, Slutsky AS. Determinants of blood pressure in snorers. Lancet 1988;ii: 992-4.

14 Hoffstein V, Chaban R, Cole P, Rubinstein I. Snoring and upper airway properties. Chest 1988;94:87-9.

$15 \mathrm{Zar} \mathrm{JH}$. Biostatistical analysis. 2nd edn. New Jersey: Prentice Hall, 1984:239.

16 Hoffstein V, Viner S, Mateika S, Conway J. Treatment of obstructive sleep apnea with nasal continuous positive pressure. Am Rev Respir Dis 1992;145:841-5.

17 Leiter JC, Knuth SL, Bartlett D. The effects of sleep deprivation on activity of the genioglossus muscle. $\mathrm{Am}$ Rev Respir Dis 1985;132:1242-5.

18 Sullivan CE, Issa FG, Berthon-Jones M, Saunders NA. Pathophysiology of sleep apnea. In: Saunders NA, Sullivan CE, eds. Sleep and breathing. New York: Dekker, 1984:299-363

19 Guilleminault C, Stoohs R, Duncan S. Snoring. Daytime sleepiness in regular heavy snorers. Chest 1991;99:40-8. 